\title{
Nature and Culture as Human Spaces
}

\author{
Thomas Storck \\ G. K. Chesterton Institute for Faith and Culture, Seton Hall University
}

\begin{abstract}
Using Tõnu Viik's statement of the relationship between philosophy and culture as a framework, after discussing both nature and world, I investigate how culture affects the ways human beings live in nature and the world, then the implications of living in culture for philosophy and human knowledge, and finally the philosophy of culture, what it is or might be and its place as a focal point for a philosophical understanding of human life and activity.
\end{abstract}

Keywords: culture, horizon, nature, Kulturphilosophie, Viik, world

\section{Introduction}

In one of his recent books Terry Eagleton (2003, 80-81) speaks of intellectuals as needing a theoretical space for discourse about "ethics, politics, aesthetics, metaphysics, everyday life and ultimate truth," and notes that philosophy once constituted that space and "indeed, it still is in those European cultures for which philosophy has not been reduced to an aridly semantic affair." Where philosophy is not "an aridly semantic affair," or has not been reduced to simply an academic discipline, of concern only to "professional" philosophers, the European philosophical tradition has been able to carry on a fruitful dialog with anthropology, history and literature, and therefore to provide intellectual space for discussion of the central questions of human existence, many of which questions are today naturally situated around the concept of culture. Yet both culture and the philosophy of culture, in part because of their very complexity, are not well understood as subjects of philosophical investigation. In his article, "What About the Philosophy of Culture?", Tõnu Viik (2000) has stated clearly the basic problematics for any philosophical understanding of culture, and therefore by extension, of culture's relations with nature and the world. Without necessarily agreeing

Corresponding author's address: Thomas Storck, 275 Mary Avenue, Westerville, Ohio 43081, USA.Email: thos51storck@yahoo.com. 
with his final conclusions, since he sets forth so clearly the fundamental relations between philosophy and culture, we may profitably use his account of the basic questions in the philosophy of culture as a way of ordering our own considerations. In the first place, let us look at Viik's statement of the relationship of philosophy with both the concept and the actuality of culture.

At the outset of his article Viik presents the situation as follows:

The explosion of the use and the meaning of "culture" seems to be a distinctive phenomenon of our time: a few centuries ago this wide meaning of the word would have made no sense to any audience... Today it has become not only a popular term, but also a term with an extremely wide content. "Culture" means practically everything which is not "from nature": the whole human world with its customs, artifacts, knowledge, material products, ideas and values. As such, culture is considered to be the most important determinant of human life. From this perspective human being seems to be essentially Inder-Kultur-Sein instead of Heidegger's In-der-Welt-Sein. It means that all human thoughts and actions are constituted by culture and the world of culture serves as a horizon for any possible activity. Consequently philosophy has no universal truths at its disposal and is nothing but an expression of the "spirit of an age". (Viik 2000, 247)

This is Viik's statement of the fundamental questions which confront an attempt at a philosophical account of culture. In the first place we should note that Viik contrasts culture with two other concepts or realities: nature and world. In order to better understand culture, we might begin by asking whether there is a distinction, and what it is, between nature and world, and what both these terms mean. Then we can more accurately look at the question of in what ways human beings live in nature (or the world) and in what ways in culture and what this means, and particularly at Viik's claim that since "all human thoughts and actions are constituted by culture" therefore "philosophy has no universal truths at its disposal"; finally at the question of the philosophy of culture itself, what it is or might be, at the claim that culture is too variable a thing for legitimate philosophical consideration, and at the philosophy of culture as an intellectual focus for philosophical reflection on human beings and societies.

\section{Existence in nature and in the world}

Before we investigate the question of whether or how human existence is In-der-Kultur-Sein or In-der-Welt-Sein, we need to examine the concept of world more closely, particularly by looking at the distinction between world and nature. Although nature, along with its various cognates in other European languages, is surely one of the most elusive of words upon which to fix 
a meaning, underlying every use of nature, whether in philosophical or popular usage, however far removed it might seem to be, is Aristotle's account in his Physics (II, 1). Aristotle created a double concept of nature, both aspects of which together provide an account of those things which can be said to exist "by nature." In the first place Aristotle states that each thing which exists by nature "has within itself a principle of motion and of stationariness (in respect of place, or of growth and decrease, or by way of alteration)." Therefore

a bed and a coat and anything else of that sort, qua receiving these designations-i.e., in so far as they are products of art-have no innate impulse to change. But in so far as they happen to be composed of stone or of earth..., they do have such an impulse, and just to that extent....

We can see from this what Aristotle meant when he said something exists "by nature." Anything possessing an inherent principle of change or motion, whether of growth or even of downward or upward movement, can be said to exist by nature. While it is true that a bed or other product of art does exhibit such a tendency of motion, this is in virtue of the material out of which the bed is made, e.g., wood or metal. For the weight of a bed, its tendency to downward movement, or the fact that a bed burns or rusts, is by virtue of the material out of which it is made, not because that material has been shaped into a bed. The bed as such has no internal principle of movement or decay, only the material out of which it is made. The fact that the wood or metal has been shaped into a bed is accidental and merely external to the wood or metal. Aristotle concludes this part of his discussion with the definition "that nature is a source or cause of being moved and of being at rest in that to which it belongs primarily, in virtue of itself and not in virtue of a concomitant attribute." (Physics, 192b).

But this is only one half of Aristotle's account of nature. For from what has been said it might seem as if nature were something like a quality or a property merely present in a thing. When Aristotle says "nature is a source or cause of being moved and of being at rest," what he means is that a thing's own nature is such a cause. This becomes clearer in his second account which begins as follows, "Another account is that 'nature' is the shape or form which is specified in the definition of the thing... Thus in the second sense of 'nature' it would be the shape or form... of things which have in themselves a source of motion" (Physics, 193a-b). But by "shape or form" he means more than the mere external shape, e.g., the external shape of a bed which is made from wood. For he says, "man is born from man, but not bed from bed. That is why people say that the figure is not the nature of a bed, but the wood is-if the bed sprouted not a bed but wood would come 
up" (Physics, 193b). As we saw above, the wood possesses its own "principle of motion and of stationariness," not the bed as such, and this principle is responsible for how it moves, grows or alters, as expressed in the scholastic maxim, agere sequitur esse, action follows being. Thus this second account of nature is complementary and presupposes his earlier account, for both understand the "principle of motion and of stationariness" in the same way.

If nature in the second sense is the "shape or form... of things which have in themselves a source of motion"-recalling that we are not referring primarily to external shape-and "which is specified in the definition of the thing," how does this occur? Whatever motion any individual thing manifests-motion here understood as an inherent tendency or capacity to change of any sort-or whatever essential characteristic of any kind it possesses, all these come from the original constitutive whatness of the thing, or indeed from its "shape or form" as Aristotle uses those terms here. For example, a piece of lead and a piece of chalk, both of the same size, will have very different weights. A piece of gold and a piece of wood will behave very differently if placed in fire. In each case this is because the thing's own constitutive whatness-its nature-determines what will be its characteristic qualities and tendencies. And ideally this whatness will be captured in its definition, "the shape or form which is specified in the definition of the thing."

But there is one further difficulty about our understanding of nature. From what I just said, it would seem as if we could speak only of the individual natures of different sorts of things, for each kind of thing has its own nature. But in fact we often speak of nature as a whole, even if we are not always clear what we mean by that. Thomas Aquinas distinguished between the nature of a particular thing and the order of created nature as a whole (Summa Theologiae I q. 110 a. 4). Thus nature can mean the entire system of natures as well as the nature of some particular type of thing.

What of world then? Here we have neither an originating account such as we have for nature, nor one single concept or idea. We may best approach this subject by returning to a consideration of Viik's text. He writes that since culture constitutes "the whole human world with its customs, artifacts, knowledge, material products, ideas and values [therefore] culture is consid-

\footnotetext{
Although because of its shape a bed or any product of art will have certain properties-e.g., a piece of wood shaped into a boomerang has aerodynamic properties that pieces of wood otherwise shaped do not have-such properties are "in virtue of a concomitant attribute," that is, accidentally, and not by nature or "in virtue of itself." Every piece of wood will have certain properties depending on its shape, and every piece of wood must have some shape or other. These are simply accidents of the wood, whose fundamental properties still determine the behavior of the object. Moreover, a boomerang made of wood will behave differently from one made of lead.
} 
ered to be the most important determinant of human life," and thus our life is In-der-Kultur-Sein, not In-der-Welt-Sein. Since "all human thoughts and actions are constituted by culture and the world of culture serves as a horizon for any possible activity," the world is swallowed up in culture or obscured by it. A culture becomes a way of viewing the world, so that in a sense we do not live in the world but in the world within or by means of our culture: "the world of culture serves as a horizon for any possible activity."

The concept of horizon is key here for understanding the way that culture affects our understanding of world. One author explains this concept as follows:

Every object appears as a definite figure against a background; it appears against a horizon of meanings. The apple which...I perceive as a unity and totality appears first as a real apple against the horizon of the table, the fruitbowl, cupboard, or book on which it lies.... Perception, therefore, is always perception of the whole thing, as integrated into a wider field which, in its turn, also is a part of a horizon of more remote meanings. It is the structure of these nearby and faraway horizons of perception which constitutes the "worldness" of the world. (Luijpen 1960, 99)

Viik's extension of horizon to culture as a whole is related to a term Husserl uses, Umwelt, which means

not the "objective world", nor the world of mathematical sciences and physics, but the world of "valid realities" (geltende Wirklichkeiten) for the subjects belonging to a particular historical-cultural community. (Viik 2014, 67)

We see here three different though related concepts of world. In the first place, world simply as something objectively existing, something not created by human agency, secondly, "the world of mathematical sciences and physics," that is, the world as reduced to relations knowable and manipulable by experimental techniques grounded in mathematics, and lastly "the world of 'valid realities'... for the subjects belonging to a particular historical-cultural community."

How do these various "worlds" relate to each other or to nature? The first sense of world would seem to underlie the other two, both of the latter being particular ways of viewing or framing the former. If we use nature to mean the entire collection of those things which exist "by nature" in Aristotle's sense, nature understood in this way relates differently to each of these three senses of world. In the first place, if we are thinking of world as simply what exists, the "objective world," we might say that it differs from nature only in that by world we simply lump together in an undifferentiated manner everything that is, without consideration of any internal principle, such as 
we have with nature. ${ }^{2}$ So in this sense, nature and world are coextensive, and include the same objects under different ways of regarding them. ${ }^{3}$ They differ in their formal object, although not in their material object. ${ }^{4}$

The second and third understandings of world, however, selectively present to us the various objects which exist one way or the other in the "objective world." And here we encounter one of the central questions of our inquiry. Viik says that since culture constitutes "the whole human world with its customs, artifacts, knowledge, material products, ideas and values [therefore] culture is considered to be the most important determinant of human life," and thus our life is In-der-Kultur-Sein, not In-der-Welt-Sein, since "all human thoughts and actions are constituted by culture and the world of culture serves as a horizon for any possible activity." Thus may we say that world in this third sense is created by culture, since any culture constitutes and validates reality, i.e., the world, "for the subjects belonging to a particular historical-cultural community"? By its selective appropriation and presentation of world in the first sense, a culture creates a world in the third sense of that term.

But here we confront another difficulty: human beings are creatures that exist "by nature," since we have in ourselves an internal principle of change. Further, since the particular nature that human beings possess is very complex and indeterminate in many ways, this very indetermination is what requires and calls forth the creation of culture. Fundamentally then culture is natural, for it is necessitated by human nature. In whatever way humans exist within culture, this presupposes an existence in nature (and in the world). Whatever modifications culture makes in our physical environment, and more importantly, whatever mental horizons or "world of 'valid realities"' any particular culture establishes for a society, it is still true that fundamen-

${ }^{2}$ What of "natural world"? This term is taken in many varying senses, and can mean the world as untouched by human culture or art, or even as an equivalent of "world" or "nature," as meaning the totality of things that possess real existence.

3 There are some things, however, whose connection with nature is unusual. Certain products of human art, such as glass or plastic, behave as if they had internal principles of their own which determine their characteristics and reactions. Wood shaped into a bed behaves the same way as a log of wood, but the sand and other materials out of which glass is made seem to be entirely lost in the new product, and they seem to have acquired a kind of "second nature."

4 Space prevents an exhaustive discussion of fictional and related objects of various kinds, possibilities, for example, or "beings of reason," things which do not really exist but are treated as existing, e.g., the hole of a donut. Possibilities, on the other hand, could exist, and can possess some kind of existence in the mind of an artist. Mathematical objects likewise belong to this general discussion. Cf. Aristotle, Metaphysics, XIII, 2-3. 
tally we must In-der-Natur-Sein. ${ }^{5}$ This is because the determinants and horizons provided by culture are rooted in nature, most importantly in human nature, and secondarily in the natures of the other things which human cultures make use of, and the totality of such natures provides limits to any culture. $^{6}$ Even though humanity's nature is less specified than the natures of other things existing in the world, still human beings live in nature and within our own human nature, even if that nature is and must always be particularized by some culture. It is the undetermined quality of human nature that allows and demands the creation of culture.

In order to understand what I mean by the undetermined quality of human nature, we can look at the case of human language. The universal aptitude of human beings for language, whatever its origins, seems at least to be consonant with human nature, whatever further one could say about it. Heidegger $(2008,397)$, making his own "an ancient pronouncement [that] we ourselves are those creatures who can speak," continues by stating that " $[\mathrm{t}] \mathrm{he}$ capacity to speak distinguishes the human being as a human being. Such a distinguishing mark bears in itself the very design of the human essence." But obviously each language is a cultural construction, no one language, as far as we know, is more natural than any other. So in order to fulfill the natural instinct or aptitude for language use, human beings must participate in a cultural construct that is arbitrary and historically conditioned, even, in some instances, consciously shaped by human decision. In order to speak, one must speak a particular language. This condition exists with regard to cultural objects and institutions in general, indeed with regard to the totality of human culture. Since human nature is less determined than the natures of other creatures, fewer aspects of human behavior are directly determined by our nature. There is more room both for choice in attaining ends, and even in choosing many of those ends. But generally some determination must be made, just as in order to speak one must speak some particular language. Even in the most primitive conditions some choices must be made as to religious rites, family and other kinship structures, food and food preparation, building materials and style of dwelling, tools, etc. All these choices are cultural choices and in fact are elements which constitute particular cultures. Therefore we can say that to live in a culture is as absolute and necessary as to live in the world. Of course when I speak of cultural "choices," most often this is not a matter of individual reflective choice, but merely of the fact that

5 As Terry Eagleton (2000, 2-3) noted, "In a further dialectical turn, the cultural means we use to transform nature are themselves derived from it."

${ }^{6}$ As Steen Brock $(2006,2)$ notes, "dass alles was gibt, auch soziale, kulturelle oder persönliche Sachen, am Ende als Formen innerhalb der einzig gegebenen Natur zu verstehen sind." 
for a particular human group choice was theoretically possible, albeit not unlimited, since the environment of any particular place limits the options available and, as I said above, the world itself (or nature) provides ultimate limits for any culture.

\section{What does it mean to live in the world of culture?}

We are now at the point where we can look at Viik's specific formulation of the question of living within a culture. He writes:

We do not need to explore further the inner logic of culture's functioning to conclude that those few philosophers who have not rejected the philosophical investigation into culture have tried to elaborate the existential aspect of culture. Their main question has been: what does it mean for a human being to live in the world of culture? (Viik 2000, 265)

If it is true that human beings necessarily live in the world (in nature) and in culture, although in different ways, what can we say that living in culture means? Earlier I had quoted Viik that "all human thoughts and actions are constituted by culture and the world of culture serves as a horizon for any possible activity. Consequently philosophy has no universal truths at its disposal..." It would seem that the question, "what does it mean for a human being to live in the world of culture," means how or to what extent does any particular culture limit or condition the way we live in the world? How or to what extent does it make our direct interaction with the world more difficult, since we see the world only through the lens of a culture? In an attempt to understand this, let us first look at a statement of what we might call the robust version of this position.

No man ever looks at the world with pristine eyes. He sees it edited by a definite set of customs and institutions and ways of thinking. Even in his philosophical probings he cannot go behind these stereotypes; his very concepts of the true and the false will still have reference to his particular traditional customs.... From the moment of his birth the customs into which he is born shape his experience and behavior. By the time he can talk, he is the little creature of his culture, and by the time he is grown and able to take part in its activities, its habits are his habits, its beliefs his beliefs, its impossibilities his impossibilities. Every child that is born into his group will share them with him, and no child born into one on the opposite side of the globe can ever achieve the thousandth part. (Benedict 1934, 2-3)

But can we not say at the outset that this statement of the question is contradicted by our own experience and by the experience of many others, indeed by the experience and scholarship of the author herself? Were her 
statement literally true, each of us would not only be imprisoned within a cultural milieu but would never even be able to perceive that imprisonment. We would be unable not only to understand another culture but even to understand why this is so. To investigate this claim of cultural imprisonment further, let us make a distinction between two types of cultural formation which people undergo. Alfred Kroeber $(1963,96)$ sketched this distinction in the following words:

The degree to which every individual is molded by his culture is enormous.... The formal or deliberate part of the process we call education: education through schools, in religion, and in manners, and morals primarily at home. These agencies convey the mores and some of the folkways. But perhaps a larger fraction of the cultural tradition is acquired by each individual at his own initiative.... In this class are his speech, bodily postures and gestures, mental and social attitudes, which he imitates from his elders or from near-age mates, and a thousand and one activities... which a child "learns," often without any formal instruction, because he has seen others do these things and wants to do them too.

The first class, that which according to Kroeber is inculcated in a "formal or deliberate" way, includes a culture's religion, political ideology, morals, all those ideas or systems of thought or belief which we are more or less aware that we adhere to. In the European cultural orbit at least, for some time it has been not uncommon for many individuals to dissent from their culture's norms in these areas. Although it is true that in some subcultural strata this has been more common than in others, still numerous individuals have differed from the norms which have held sway in their societies in religious, political, moral and the other spheres constituted, at least in part, by conceptual knowledge.

Kroeber's second sort, that "which a child 'learns', often without any formal instruction," includes our "speech, bodily postures and gestures, mental and social attitudes," matters such as how close we stand when talking to another person, whether we smile at or greet strangers on the street and so on. Indeed, Kroeber has an unusual instance of this in the following: "The Japanese carpenter pulls the plane toward himself, centripetally. The Western workman pushes it away from his body, centrifugally" (Kroeber 1963, 156). All these latter types of cultural traits are hard to identify or specify, and because of this they are likely to be more deeply rooted than something which can be recognized and conceptualized. Many of them are formed as a child, even before the ability to talk, and one could not possibly come up with a complete list of them. Therefore one is much less likely to depart from his culture's norms in such matters, even should one desire to do so, for only with difficulty can we realize the very existence of such norms. Nor 
do they concern simply external personal, physical or interpersonal conduct, for there are certain habits of thought, elusive but still real, which fall into this category. For example, a European who becomes a Hindu is likely to carry over unbeknownst certain Western attitudes whose existence he will probably not even discover or realize until some concrete question or dilemma is being faced. This is even the case within European civilization when we contrast mental habits of historically Catholic cultures with those of historically Protestant cultures. And even if one could identify and had resolved to change such subtle aspects of behavior, it is likely that for some time this would require a much more conscious attention to one's conduct and mental or emotional reactions than is usual, nor is it clear that one could be entirely successful in effecting such changes.

Therefore while we can alter certain types of behavior easily enough, it is not so easy to think or feel according to cultural patterns that are not native. But we must be careful not to overstate the situation. For several centuries at least, the numerous differences among cultures and the ways of living and thinking which result from them have been recognized in European thought. And many investigators have been able to enter, to some degree, other cultural worlds, different either in place or in time. The ease and success of doing so vary according to both the ability of the anthropologist or historian or philosopher-or even the traveler or the casual reader-to recognize his own cultural assumptions and his ability to grasp the fundamentals of the new culture. But probably few would deny that this has been achieved, more or less successfully, at least to some degree. The difficulty and danger are that it is easy to imagine that one has transcended one's own culture while not recognizing the subtle ways or the degree that most of us have been shaped by the cultures of our upbringing. Actual experience of living in more than one culture, especially when one is young, can doubtless be an invaluable aid in perceiving the many cultural assumptions and habits which are picked up unawares. Sometimes even when we understand that a certain type of behavior is culturally formed, it is not easy to abandon it and even less easy to understand or adopt the mentality or unconscious habits of a different culture. Still I think we can conclude that to some extent we can transcend our particular culture and realize some of the various cultural options that are available to human nature. In this respect, then, to live in culture is not an absolute in the same way that to live in nature or the world is. While all, or nearly all, human acts are mediated through some particular culture, the hold of any particular culture upon any individual human being need not be complete.

Moreover any ability to transcend cultures depends upon commonalities in human nature. Even a proponent of the system called Universalism, 
which calls itself a metaphilosophy and whose "goal...is to proceed from a standpoint that recognizes and includes not only all the philosophies but also all the possible philosophical points of view [and which] aspires to include within its perspective the universal insight of all the religions, ideologies, and cultures of the world," (Mitias 2004, 92) admits that there is a certain human nature in which all human experience is grounded, even if, as we have seen, this human nature operates or manifests itself according to some particular cultural norm or context.

\begin{abstract}
It is true that one views and experiences the world from the standpoint of his or her culture, but it is equally true that one views and experiences the world as a human being. Regardless of their cultural orientations, in the past or the present, think of how people react similarly to phenomena such as love, hate, death, disease, pleasure, suffering, survival, order, chaos, family, justice, success, failure, to mention some examples. Are these not essentially human experiences? (Mitias 2004, 90)
\end{abstract}

The essentials of the human species are one, and regardless of the various determinations made by the many cultures, past and present, of our common human nature, such determinations are within definite bounds. Just as we recognize individual differences so we recognize cultural or societal differences, but all within the bounds allowed by human nature and the world itself.

If we have shown that to some extent people can and do transcend their native cultural boundaries, we still must consider Viik's further statement that because of the ubiquity of culture in human life "philosophy has no universal truths at its disposal." For despite the ability to transcend our cultural limits that we have just examined, it does not necessarily follow that we have attained to real knowledge of the world or to any "universal truths" which the human intellect can discover. If we merely escape from one subjective cultural world only to enter into another, equally subjective, we will have done little to approach such "universal truths." Therefore we must discuss not only our ability to transcend a particular cultural environment, but to achieve some measure of knowledge of the real.

Thus on the one hand we have the epistemological question, the question of how and to what extent human beings as such can know, and on the other, the question of how cultures can affect or distort this thinking and knowing. The first question is beyond the scope of this paper, but insofar as culture impedes or distorts human knowing, it functions somewhat after the manner of Bacon's Idols of the Market-place or Idols of the Theatre, factors which arise from human language or intellectual traditions. ${ }^{7}$ A culture can inculcate

7 See The New Organon, book I, aphorisms XLIII, XLIV and LIX-LXII. 
and transmit falsehoods or confusions, but given the commonality of human nature, cannot change the fundamental constitution of the human body or mind. One may reasonably ask whether some cultures perceive certain aspects of reality better than other cultures, but just as many persons have gone beyond the specific cultural boundaries within which they were formed, so, with patience and sufficient care, we can, at least in part, overcome any barriers to the attainment of truth erected by any particular culture. In the case of philosophy, as in other areas of thought and conduct, one should proceed with caution, but we are not necessarily prevented from recognizing truths simply because they are inconsistent with the Idols of our own particular market-place or theatre. Some truths, moreover, such as the principle of non-contradiction, would seem to be implicitly assumed in all human discourse, regardless of whether or how they are explicitly recognized. ${ }^{8}$ Thus while we can admit that, in a certain respect, "all human thoughts and actions are constituted by culture and the world of culture serves as a horizon for any possible activity", it is going too far to claim that "philosophy has no universal truths at its disposal," for people both can and have, in varying degrees, transcended any cultural limitations that might inhibit knowledge of the real. Therefore "to live in the world of culture" is not a sentence of intellectual imprisonment but a necessary feature of human nature and life. To the extent that it can limit us, we have the power of overcoming this limitation, even if not perfectly, and even if this very ability must be exercised according to intellectual norms validated within a particular culture. But on that account to resent the existence of human cultures and their formative powers is to reject the freedom inherent in human nature, a freedom which not only requires the existence of cultures, but gives us our capacity, even if not unlimited, to transcend their boundaries and modes of determination, both in order to enter into other cultures and to attain to truths which are grounded in the nature of things and thus transcend any particular cultural determination.

8 Although a thorough discussion of this point is beyond the limits of this paper, I suggest that it is simply not possible for a human mind to function without these basic principles, not because, as with Kant, our minds our structured accordingly, but because we simply recognize that reality contains or manifests or exemplifies these principles, so that we cannot understand or speak of it otherwise. Without at least an implicit assumption of the principle of non-contradiction, the principle of identity, etc., one could hardly write a coherent paragraph advocating something. Anyone seeking to deny them would necessarily presuppose them, whether this was recognized or not. 


\section{Philosophy's concern with culture}

Viik raises another question which in a way is the exact opposite of the one we have been considering. He puts it in this way:

Traditionally culture has not been a serious subject matter for philosophy. Philosophy has been committed to divine, eternal and unchangeable things, while culture's nature is obviously different. According to Plato's allegory of the cave, culture consists of the twaddle of people who talk about the shadows on the cave's wall. In this, Aristotle also remained true to the view of his teacher. He claimed that true philosophical knowledge concerns substances which are not accidental, but necessary and eternal. (Viik 2000, 248)

And Viik further quotes Aristotle, "That there is no science of the accidental is obvious." I said that this in a way is the opposite of the question we just considered at length, in which we examined, from the standpoint of the existence of varying cultures, the ability of the human mind to know universal truths. This present question, however, seems to presuppose the ability of philosophy to attain to "divine, eternal and unchangeable things," in fact to transcend culture, while at the same time to ignore it as unworthy of philosophical interest. Even if we largely accept, as I do, Aristotle's understanding of scientific knowledge, we are not forced to conclude that culture cannot be "a serious subject matter for philosophy." In fact, the dilemma, as Viik states it here, is unnecessary. In a way much of culture does consist "of the twaddle of people who talk about the shadows on the cave's wall," but so does much other human activity, whether of human beings considered as individuals or as part of a polis, but both individuals and political societies were important philosophical topics for both Plato and Aristotle. Human beings and societies are always in a state of flux, but these have almost always been one of the chief concerns of philosophers. This is because there are certain constants in human beings and their behavior which are proper concerns of philosophy. But, as we saw, so much of human life is colored by our cultures that it hardly seems possible for philosophy to study humanity without also studying human culture. If philosophy considers political communities as proper objects of study, then it is hard to see why it would not likewise consider cultures as properly falling within its concern.

As long as human beings are constituted in the way we are now, human nature will remain what it is; hence the necessity of culture and thus a proper philosophical interest in culture. But if culture is a proper matter for philosophic consideration, how exactly is this so? What is or what should be the philosophy of culture? We may take it as given that there is no general agreement on this question. As Steen Brock (2006, 8) aptly said, "Denn, was heisst Kulturphilosophie? Es gibt wohl keine allgemein akzeptierte Defini- 
tion von dies!" Even though it is the case that the philosophy of culture has no generally accepted meaning, is it possible to draw out certain points from our understanding of culture which would seem to be worthy of philosophic interest?

Philosophy has long been interested in human beings as part of nature, with human nature itself, with our perception of the world around us and with the limitations of human knowing. But if "human being seems to be essentially In-der-Kultur-Sein," then all such philosophical questions are affected, to one degree or another, by Viik's question, "what does it mean for a human being to live in the world of culture?" How does culture constitute our existence as human beings, how does it affect our relationship with the world or with nature? How do cultures themselves, understood as more or less coherent systems, reinforce cultural norms and how do the institutions and customs of a culture manifest that culture's understanding of the world? Philosophy moreover may fruitfully look at questions such as how a culture determines or conditions human nature, how culture creates a human space and whether some cultures do so in a more healthy manner than others. All these seem both appropriate and interesting topics for philosophical investigation and constitute proof, in my opinion, that not only is the philosophy of culture an entirely legitimate part of philosophy but one that may contribute much to our knowledge of reality.

If human beings must live in culture as surely as we must live in the world, then culture also offers us a human space, a space within which to live our lives, both individually and socially. Even though cultures are not closed systems, they are still the principal spaces within which we live. That the space provided by culture is more complex, both in its relations with human nature and with the world seems to be an inescapable conclusion. But if so, then all the more do such space and such relations deserve the attention of philosophy. If "human being seems to be essentially In-der-Kultur-Sein," culture is the unique focal point and place for human action. Even someone setting out to transcend his own culture must begin with that culture. Thus one can hardly understand humanity in its fullness without an equally clear understanding of the matrix in which we all live.

\section{Conclusion}

At the outset I quoted Viik that

The explosion of the use and the meaning of "culture" seems to be a distinctive phenomenon of our time: a few centuries ago this wide meaning of the word would have made no sense to any audience.... Today it has become not only a popular term, but also a term with an extremely wide content. 
It is hardly unusual for philosophers to take up an interest in things which are new, or as in the case of culture, newly designated or understood. Technology, the nation state, economics, human rights-all these have become subjects of philosophical interest in the last century or so. It may be true that "there is nothing new under the sun" (Ecclesiastes 1:9b) because the natures of things do not change, but there are certainly new configurations of things and, more importantly, new ways of understanding things. If in the past culture was not singled out as a subject of study or hardly even recognized as something that existed, this is not because it was not the omnipresent conditioning force in human life and history then as it is now. Indeed, it has always been and inescapably so. Philosophy therefore must investigate something as central to human life and society as culture if philosophy is to hope to retain the place in education, and indeed in civilization, as an interpreter of reality, that it deserves to have.

\section{Bibliography}

Aquinas, T. (1885). Summa Theologiae, Marietti, Turin.

Aristotle (1952). Physics in The Works of Aristotle, Vol. 8 of Great Books of the Western World, Encyclopaedia Britannica, Chicago.

Bacon, F. (1955). The New Organon in Selected Writings of Francis Bacon, Modern Library, New York.

Benedict, R. (1934). Patterns of Culture, Houghton Mifflin, Boston.

Brock, S. (2006). Kulturphilosophie: Bohr, Cassirer, Wittgenstein, Cavell, MacIntyre, Winch, Taylor [und] Haraway: Sechs Vorlesungen am Humboldt Universität zu Berlin.

URL: http://pure.au.dk/portal/files/41412787/kulturphilosophie.pdf

Eagleton, T. (2000). The Idea of Culture, Blackwell, Oxford.

Eagleton, T. (2003). After Theory, Basic Books, New York.

Heidegger, M. (2008). The way to language, Basic Writings, HarperCollins, London.

Kroeber, A. (1963). Anthropology: Culture Patterns and Processes, Harcourt, Brace \& World, New York.

Luijpen, W. (1960). Existential Phenomenology, Duquesne University, Pittsburgh.

Mitias, M. (2004). Universalism as a metaphilosophy, Dialogue and Universalism 14: 87-101. 
Viik, T. (200o). What about the philosophy of culture?, Acta Philosophica Fennica 65: 247-271.

Viik, T. (2014). Husserl's account of the cultural uniqueness of western civilization, in V. Lang and K. Kull (eds), Estonian Approaches to Culture Theory, University of Tartu, Tartu, pp. 66-84. 